\title{
Sensibilização para o teatro: experiência com alunos do curso técnico de eventos
}

\section{Awareness to theater: experience with students of technical course in events}

Recebido: 10/04/2020 | Revisado: 10/06/2020 | Aceito: 15/06/2020 | Publicado: 19/04/2021

Maria Carolina de Andrade José ORCID: https://orcid.org/0000-0002-6318958X

Universidade de São Paulo

E-mail: mariandrade.j@hotmail.com

Como citar:

JOSE, M. C. A. Sensibilização para o teatro: experiência com alunos do curso técnico de eventos. Revista Brasileira da Educação Profissional e Tecnológica, [S.I.], v. 1, n. 20, p. e9886, abr. 2021. ISSN 2447-1801.

This work is licensed under a Creative Commons Attribution 4.0 Unported License.

\section{Resumo}

O presente texto apresenta os resultados obtidos a partir de uma visita técnica realizada com alunos do curso técnico de Eventos da ETEC Parque Belém ao Espaço Sobrevento de Teatro. Os alunos assistiram ao espetáculo "Noite", e em seguida participaram de um debate com os atores da companhia e uma discussão em sala de aula sobre a visita técnica. Outro elemento utilizado como ferramenta para apreensão da experiência dos alunos foi um breve questionário, aplicado posteriormente. Desse modo, foi possível compreender que esse tipo de prática pedagógica possibilita $o$ desenvolvimento da sensibilidade $e$ criatividade dos alunos, além de ampliar o leque cultural e técnico relacionado a Eventos.

Palavras-chave: Educação profissional; Eventos; Visita técnica; Cultura; Teatro.

\section{Abstract}

This text presents the results obtained from a technical visit carried out with students from the ETEC Parque Belém Events technical course to the theater Espaço Sobrevento. The students watched the show "Noite", and then participated in a debate with the company's actors and a discussion in the classroom about the technical visit. Another element used as a tool to understand the students' experience was a brief questionnaire, applied later. This was possible to understand that this type of pedagogical practice enables the development of students' sensitivity and creativity, in addition to expanding the cultural and technical range related to Events.

Keywords: Profesional education; Events; Technical visit; Culture; Theater. 


\section{INTRODUÇÃO}

A visita técnica aqui descrita foi realizada com a turma do primeiro módulo do curso técnico de Eventos da ETEC Parque Belém. O curso técnico de Eventos foi formulado a partir do Catálogo Nacional de Cursos Técnicos desenvolvido pelo Ministério da Educação (MEC), que considera o profissional de eventos como aquele que "projeta, planeja, organiza, coordena, executa e avalia serviços de apoio técnico e logístico a eventos de diversas classificações e tipologias" (BRASIL, 2016).

A disciplina de Produções de Eventos Culturais, inserida no currículo do curso técnico em Eventos das ETEC, propõe o desenvolvimento das seguintes competências: analisar a influência da cultura, do patrimônio, do tombamento e dos museus na realização de eventos; valorizar as manifestações populares do Brasil na concepção e produção de eventos; e analisar aspectos da arte e seus diversos estilos, na organização e decoração de eventos artísticos culturais (CEETPS, 2013).

Nesse contexto, é necessário incentivar uma maior aproximação dos alunos com o amplo leque de atrações culturais disponíveis na cidade de São Paulo, buscando incentivar os alunos a frequentar espaços e atividades culturais e desenvolver o conhecimento técnico relativo a eventos culturais.

Carvalho (2016) considera que a experiência teatral "pode desenvolver a criatividade, criticidade, imaginação e autonomia, em especial quando é apreciada com o acompanhamento de um professor/mediador responsável por dialogar com os alunos/espectadores" (CARVALHO, 2016, p. 10).

Ideia que se conecta a de que para acompanhar as frequentes mudanças do mercado, o profissional de eventos precisa ser dinâmico, decidido, criativo, imaginativo e desenvolver habilidades de inovação e improvisação (ONISHI, 2005).

Nas primeiras aulas da disciplina, ao aplicar uma avaliação diagnóstica, busco saber quais equipamentos culturais os alunos frequentam, já visitaram ou apenas ouviram falar, além de questionar sobre os hábitos de lazer dos estudantes. Nesse contexto, foi possível perceber que a maior parte dos alunos costuma realizar atividades caseiras no seu tempo livre: assistir filmes, acessar as redes sociais, ler livros, cozinhar, entre outros.

Quando se trata de espaços culturais, como centros culturais, teatros, casas de shows e museus, os alunos alegam frequentá-los raramente. São poucos aqueles que dizem frequentar e estar inteirados sobre a programação cultural da cidade de São Paulo. E especificamente, quando questionados sobre peças de teatro, a maioria relata ter ido poucas vezes, apenas no ensino fundamental ou em peças infantis, para levar os filhos.

Os estudantes também não conhecem ou até mesmo não ouviram falar da maior parte dos equipamentos. Pensam, também, que o acesso à cultura está inerentemente conectado ao âmbito financeiro, ou seja, consideram que tais atividades são caras, inacessíveis.

Com o objetivo de ampliar o capital cultural do grupo de alunos, como ferramenta para desenvolvimento da carreira na área de Eventos, planejei três visitas técnicas a equipamentos culturais durante o primeiro semestre dessa turma.

O presente artigo relata a experiência da primeira dessas visitas técnicas - ao Espaço Sobrevento de Teatro. O texto é divido em um capítulo sobre o cenário do mercado de Eventos e a educação profissional na área; o seguinte, que descreve o 
processo metodológico da pesquisa; um capítulo que aborda a história da companhia de teatro e seu espetáculo; outro que explica os resultados da visita técnica e o processo de sensibilização pelo teatro; e um capítulo com as considerações finais e sugestões para pesquisas futuras.

\title{
2 EDUCAÇÃO EM EVENTOS
}

De acordo com o guia de profissões técnicas desenvolvidas pelo Centro Paula Souza, instituição que gere as Escolas Técnicas de São Paulo (ETECs) o profissional de eventos é:

\begin{abstract}
Responsável pela organização, planejamento e execução de eventos de pequeno e médio porte, como casamentos, formaturas, campeonatos esportivos, palestras, shows e cerimônias públicas e privadas. Faz decoração e cuida da montagem de desmontagem dos ambientes. Elabora roteiros e aplica protocolo de cerimonial; opera ferramentas de marketing e divulgação. Elabora relatórios técnicos e de resultados, auxilia na administração de fornecedores e faz gestão de pessoas no salão (CEETEPS, 2020, p. 39).
\end{abstract}

De acordo com o Catálogo Nacional de Cursos de Tecnologia (BRASIL, 2016) fazem parte do eixo tecnológico da área de Hospitalidade e Lazer os cursos de Eventos, Hotelaria, Gastronomia, Turismo, e Lazer e Recreação.

A partir dos anos 1990, o mercado de Eventos cresceu significativamente no Brasil. Zitta (2014) considera evento como "um acontecimento onde se reúnem diversas pessoas com os mesmos objetivos e propósitos sobre uma atividade, tema ou assunto" (p. 23).

Tendo recebido megaeventos como a Copa do Mundo em 2014 e os Jogos Olímpicos em 2016, o país expandiu a infraestrutura e o mercado de eventos. Assim, a procura por profissionais capacitados e consequentemente, por cursos na área também aumentou.

No contexto nacional, São Paulo é a cidade que mais concentra eventos, principalmente congressos e eventos empresariais. No ranking elaborado pela ICCA (International Congress and Convention Association) em 2018, que considera congressos e eventos internacionais ao redor do mundo, São Paulo ocupa o 1ำ lugar no Brasil e o 3ํlugar na América Latina.

Em relação ao mercado global de eventos, o país caiu uma posição no ranking. Já que o número de eventos internacionais recebidos pelo Brasil tem se mantido nos últimos anos, enquanto outros países estão crescendo no mercado (SPTURIS, 2019).

Em período de retração econômica, a crise atingiu a todos os mercados, inclusive o de Eventos e serviços complementares. Apesar disso, o mercado de eventos se manteve em alta nos últimos anos, mostrando características específicas do consumidor brasileiro. 
O mercado de festas e cerimônias continuou crescendo, apesar do cenário econômico. Segundo pesquisa da $\mathrm{ABEOC}^{1}$, setor de eventos sociais faturou mais de $\mathrm{R} \$ 16$ bilhões, em 2018.

Apesar do crescimento promissor, a educação em Eventos ainda carece de pesquisas acadêmicas e materiais adequados aos cursos técnicos. Na área, existe insistente repetição de dados e conceitos em várias publicações, apesar da dinamicidade do mercado e das novas exigências do consumidor. Nas revistas acadêmicas especializadas, sobre turismo e hospitalidade, pouco se publica sobre eventos e menos ainda sobre a educação profissional na área.

Há também poucos estudos sobre o público de estudantes de cursos técnicos do Eixo de Hospitalidade e Lazer e sua absorção pelo mercado. Dentre esses, se destaca a interessante pesquisa de Carvalho e Rejowski (2012) sobre os estudantes egressos do curso tecnólogo de Eventos da Faculdade Hotec, especializada na área de Hotelaria e Turismo, localizada em São Paulo.

Sobre o perfil do profissional de eventos parece haver um consenso entre diversos autores. O profissional de eventos deve ser antenado e proativo com as tendências e mudanças do mercado, deve possuir boa apresentação pessoal, ser criativo, ter raciocínio lógico, percepção aguçada, espírito de liderança, saber lidar com imprevistos e desafios, ter capacidade de planejamento e organização, além de conseguir gerenciar conflitos (MARTIN, 2015).

Segundo Oliveira (2016, p. 37):

O perfil profissional para o setor de eventos demanda pessoas que tenham habilidades como administrar pessoas e contratos, negociar, ser pró-ativo, organizado, saber delegar, ter comunicação clara e objetiva, identificar perfis e ser uma reconhecedora do comportamento humano, ter sensibilidade, ser controlado, saber exatamente os objetivos do evento, tomar decisões rapidamente (com ciência das consequências), resolver problemas, ser detalhista, saber regras de etiqueta e cerimonial, ser observador e harmonizador, saber ouvir e ser conhecedor do mercado de eventos, entre outras habilidades.

O mercado exige talentos dignos de um super-herói, considerando que são habilidades primordiais para atuar em uma função essencialmente dinâmica. Cabe aos professores e pesquisadores da área, então, buscar por ferramentas que possibilitem, ou ao menos incentivem, o desenvolvimento dessas múltiplas aptidões no estudante.

Proponho, então, que conhecer, investigar e participar de atividades artísticas pode possibilitar o desenvolvimento de algumas dessas habilidades, não só no âmbito profissional, mas socioemocional.

Para fugir do aspecto funcionalista e utilitarista da educação profissional, é importante lembrar que ao desempenhar a função docente, o professor não está apenas ensinando determinados conteúdos, mas está formando indivíduos. É através

\footnotetext{
${ }^{1}$ Disponível em: <https://www.terra.com.br/noticias/dino/mercado-de-eventos-cresce-e-industriasbrasileiras-investem-no-segmento-para-consolidar-novosnegocios,459b0c9114285bda4cf70ecfac4dbd33atsmo5h1.html>.
} 
da aprendizagem que o homem se humaniza, na apropriação do conhecimento que a individualidade e suas subjetividades se desenvolvem (MEIRA, 1998).

A educação enquanto um processo ao mesmo tempo social e individual, genérico e singular, é uma das condições fundamentais para que o homem se constitua de fato como ser humano, humanizado e humanizador (MEIRA, 1998, p. 68).

As próprias Diretrizes Curriculares para a Formação Profissional, estabelecidas pelo MEC, consideram a formação profissional a partir de um âmbito globalizante, buscando o desenvolvimento de uma formação integrada a elementos sociais, culturais e científicos, "opondo-se, portanto, a uma formação meramente técnica, despregada do conjunto das práticas sociais onde as relações econômicas se organizariam e alcançariam sentido" (MUSSI, 2018, p.11).

Pretende-se assim, formar profissionais capazes de construir novos conhecimentos e desenvolver novas competências, para corresponder a complexidade e abrangência requerida pela vida social, como um todo.

\section{METODOLOGIA}

A visita técnica foi realizada dia 15 de março de 2019, com a turma do primeiro módulo do curso técnico de Eventos da ETEC Parque Belém e teve início às 19 horas. Encontrei os alunos na catraca do metrô Bresser-Mooca e caminhamos juntos até o Espaço Grupo Sobrevento de Teatro.

Optei por encontrar os alunos no metrô porque, apesar da proximidade apenas dez minutos de caminhada, trata-se de uma região com pouco movimento à noite e que é considerada perigosa. O grupo disse não conhecer a área, apesar de se tratar do mesmo bairro em que a escola fica localizada. É comum os alunos do noturno morarem em bairros distantes da ETEC e não conhecerem os equipamentos de lazer e patrimônios do bairro Belenzinho.

O Grupo Sobrevento foi escolhido por estar próximo à ETEC Parque Belém e trabalhar com a história e identidade do bairro. Além disso, a ida a uma peça de teatro pôde apresentar aos alunos uma nova forma de produção cultural, já que muitos dos estudantes não estão habituados a esse tipo de linguagem artística.

Nesse contexto, o grupo assistiu ao espetáculo "Noite" no Espaço Grupo Sobrevento de Teatro e depois debateu sobre a peça com o elenco. Os ingressos foram reservados antecipadamente e não geraram nenhum custo. Como introdução, ao chegar ao espaço os questionei sobre a frequência com que iam ao teatro e outras atrações culturais na cidade. A pergunta gerou um debate sobre a amplitude das opções culturais e artísticas disponíveis a baixos preços em São Paulo e sobre a falta de interesse (ou acesso) de grande parte da população em tais atividades.

Entre outros questionamentos, os alunos perguntaram: Quem mantinha o espaço do grupo Sobrevento? De onde veio a arrecadação para a produção? Como 
eu soube de tal espetáculo? Por que tantos deles não frequentam produções culturais, se muitas são gratuitas ou de baixo custo?

Falei brevemente sobre as leis de incentivo à cultura e sua importância para o setor de produções culturais; os informei sobre alguns dos principais canais de divulgação de atrações gratuitas na cidade de São Paulo (Catraca Livre, Guia da Semana, Sampa Online e etc.). A última questão suscitou uma discussão mais extensa sobre as barreiras do lazer: econômicas, sociais e culturais.

O grupo de 31 alunos, com idade entre 15 e 50 anos, assistiu ao espetáculo e posteriormente, teve a oportunidade de participar de um debate com o elenco da peça sobre os temas que perpassam a trama, o processo de pesquisa e construção do espetáculo, cenário, figurino e sonoplastia.

\section{GRUPO SOBREVENTO DE TEATRO}

O Grupo Sobrevento de Teatro foi formado em novembro de 1986. Mantém um extenso repertório de espetáculos e se dedica à pesquisa, teórica e prática, da animação de bonecos, formas e objetos. Com um trabalho estável e ininterrupto desde sua fundação, o grupo tem se apresentado em mais de uma centena de cidades, em 19 estados brasileiros, abordando diferentes temáticas. O Sobrevento desenvolve, além de seus espetáculos, diversas atividades no campo do Teatro de Bonecos e de Animação, como a realização de cursos, oficinas, palestras e mesas-redondas, no Brasil e no exterior (SOBREVENTO, 2019).

\section{ESPETÁCULO “NOITE”}

Noite é um espetáculo sobre a memória do bairro do Belenzinho e as memórias individuais e subjetivas, aquelas lembranças que cada sujeito carrega junto a seus objetos e histórias.

Sandra Vargas, diretora da peça, conta que o grupo convocou os vizinhos a contarem suas vidas, com o projeto "Museu da Vizinhança". "A regra era que as memórias tinham que vir de objetos pessoais." Foram reunidos objetos variados: peças de decoração, instrumentos musicais, roupas, fotos, entre outros - junto ao relato dos donos (O ESTADO DE SÃO PAULO, 2019). 
Figura 1: Grupo Sobrevento no espetáculo criado a partir de histórias da vizinhança

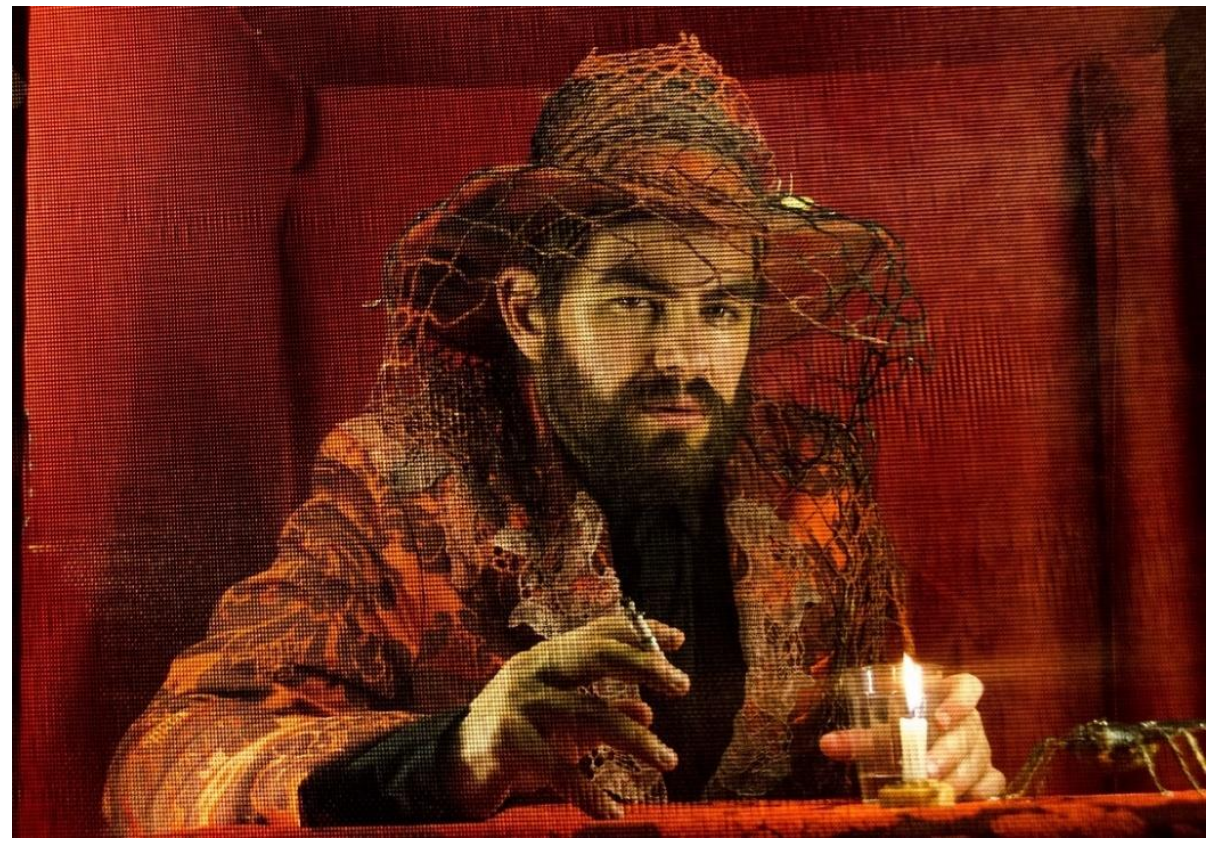

Fonte: O Beijo ${ }^{2}$

O Grupo Sobrevento de Teatro também recolheu depoimentos em espaços públicos do bairro - a feira, um velório, uma igreja, entre outros. Buscando assim compreender de que forma os indivíduos lidam com suas próprias memórias e quais são histórias eleitas como merecedoras de compartilhamento. O projeto foi contemplado pela $31^{\text {a }}$ edição do Programa Municipal de Fomento ao Teatro da cidade de São Paulo.

O grande desafio do grupo foi selecionar e amarrar os depoimentos escutados buscaram a dramaturgia nas histórias cotidianas, sem perder a simplicidade. $\mathrm{O}$ cenário fixo se constitui em um mosaico de histórias, caixinhas de lembranças. Entrelaçado pelos figurinos, assinados por João Pimenta, remetem à religiosidade flores, vestidos brancos, asas e penas.

\footnotetext{
2 Disponível em: <https://obeijo.com.br/teatro-grupo-sobrevento-estreia-noite-espetaculo-criado-apartir-de-historias-da-vizinhanca/>
} 
Figura 2: Grupo Sobrevento no espetáculo criado a partir de histórias da vizinhança

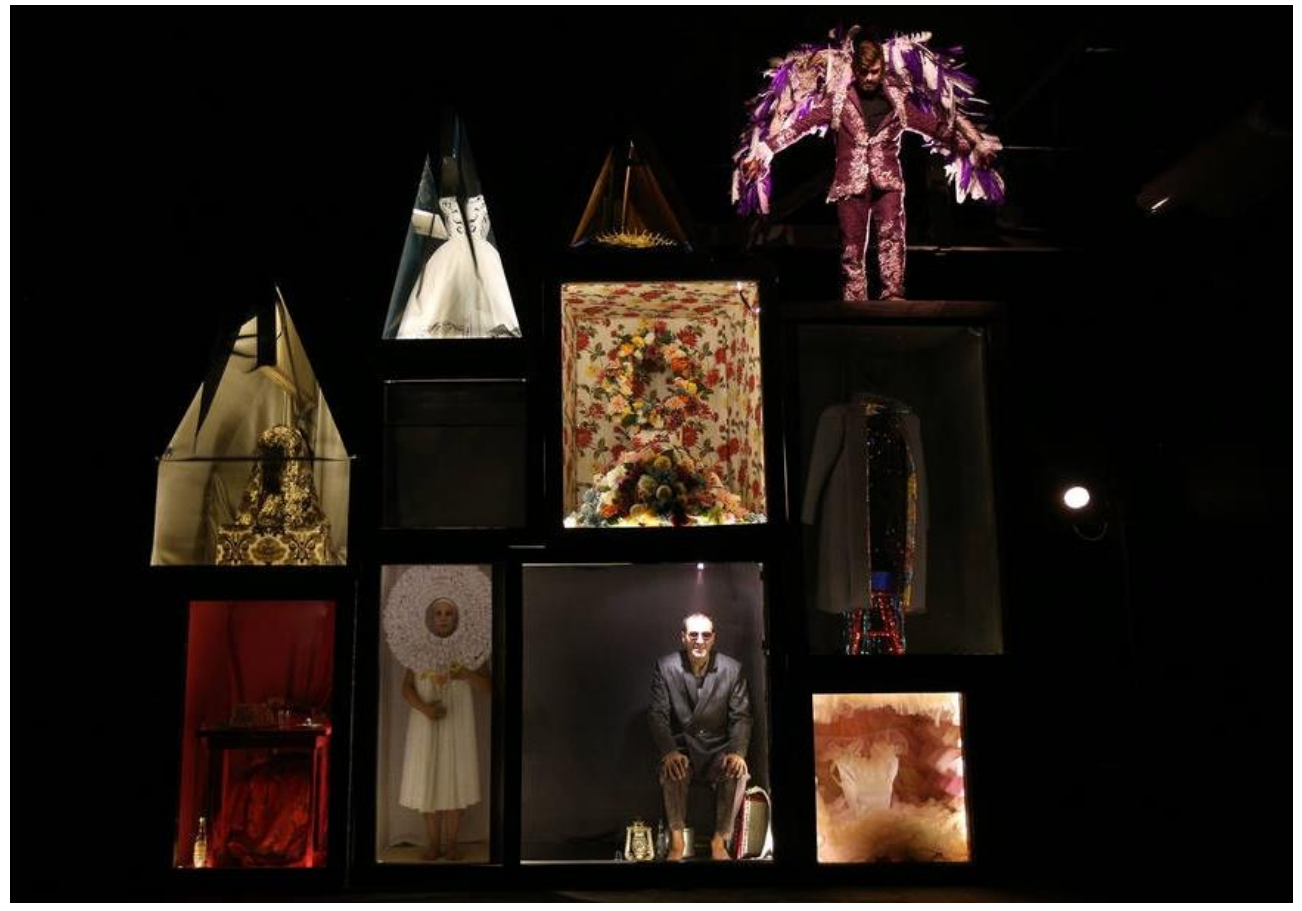

Fonte: JF Diorio/Estadão ${ }^{3}$

Segue trecho da sinopse apresentada no site do Grupo Sobrevento (2019):

Em cena, um homem cego conversa com um menino e sua fala é atravessada por suas memórias. O cenário composto por onze nichos de tamanhos variados, sobrepostos, torna possível contemplar na cena todas as personagens que compõem a memória desse homem. A princípio a luz ilumina cada figura por vez, dando vida a uma determinada memória, mas como um processo típico do pensamento humano, há momentos em que as memórias se misturam, se interrompem ou aparecem de forma fragmentada. Cada ator representa a potência máxima dessa memória, carregando em seu nicho elementos visuais que remetem ao pensamento do homem cego (SOBREVENTO, 2019).

Estáticos em seus nichos, os atores dão ênfase ao drama das histórias em si e de seus sujeitos/personagens. Como num museu vivo, se dá maior importância a cada objeto, gesto e palavra. O público acompanha, assim, as histórias seguindo o fluxo da memória dos donos dos objetos.

\footnotetext{
${ }^{3}$ Disponível em: <https://cultura.estadao.com.br/noticias/teatro-e-danca,em-noite-grupo-sobreventoecoa-memorias-de-vizinhos,70002704241>.
} 


\section{SENSIBILIZAÇÃO PARA O TEATRO}

Sou professora do eixo de Lazer, turismo e hospitalidade há apenas dois anos, mas trabalho com teatro há mais de dez anos. Iniciei meu envolvimento com teatro bem nova, aos seis anos, como espectadora. Meus pais, adoradores da arte, sempre me levaram a teatros, museus e diversos espaços culturais desde muito cedo. Aos 15 anos entrei em meu primeiro grupo de teatro e sigo atuando até hoje. Sempre me senti confortável nesses espaços: seja no palco ou na plateia, sempre busquei compreender, interpretar e, principalmente, sentir.

Ao iniciar minha atuação como professora, reconheci como missão aumentar o capital cultural de meus alunos do curso de Eventos - ao perceber que a maioria deles não frequenta, ou sequer conhece, tais espaços. Incentivando-os a frequentar espaços culturais das cidades, sempre passo dicas de programas gratuitos ou de baixo custo disponíveis no fim de semana. Nesse caso, a disciplina de Produções de Eventos Culturais cria a oportunidade ideal para desenvolver visitas técnicas que apresentem tais espaços aos alunos.

No primeiro semestre de 2019, levei o primeiro módulo de Eventos a três visitas técnicas: ao espetáculo "Noite" no Espaço Sobrevento, ao espetáculo "Mau lugar" no Teatro de Arena Eugênio Kusnet e ao Museu Emma Klabin. Sendo que "Noite" foi a primeira visita técnica da disciplina com essa turma.

De acordo com Koudela (2008, p. 3):

Os espaços culturais na cidade são ilhas de liberdade diante da ocupação da fantasia pela mídia e a sociedade de consumo. Ir a exposições e espetáculos de teatro e música é ensinar que [...], além das áreas verdes, há espaços na cidade que merecem ser visitados.

Escolher um espetáculo para agradar essa turma foi um desafio, já que se trata de um grupo heterogêneo, que possui desde adolescentes de 15 anos até adultos com cerca de 50 anos. Como sensibilizar sujeitos tão diferentes, com trajetórias tão distintas? Ou ainda mais importante, como incentivar o hábito do teatro naqueles que já são adultos?

Dos presentes, quatro alunos nunca tinham ido ao teatro; a maioria tinha ido apenas uma ou duas vezes e apenas cinco ou seis tinham o costume de frequentar espetáculos do tipo. Aqueles que tinham ido poucas vezes ao teatro disseram ter ido com a escola ou ido a um espetáculo de grande porte (musicais ou comédias populares), não conhecendo nenhum espaço teatral intimista ou alternativo.

A chegada ao teatro Sobrevento gerou uma série de comentários: "Tem certeza que é aqui?"; "Nunca imaginei que existia um teatro aqui!"; "Nossa! Que pequeno!"; "Onde fica o auditório?", entre outros.

Localizado em uma rua residencial, com pequenos comércios no bairro do Belenzinho, o espaço do Grupo Sobrevento trata-se de um galpão, com portas de ferro, ocupado pela companhia. Em uma sexta-feira à noite, a rua estava vazia $e$ 
pouco iluminada, chamando atenção apenas para a padaria no fim da rua. $\mathrm{Na}$ ocasião, a pequena recepção contava com uma exposição de fotos e uma bancada, onde se vendia café, doces e salgados, além da simples bilheteria.

Figura 3: Oficina com o Grupo Sobrevento

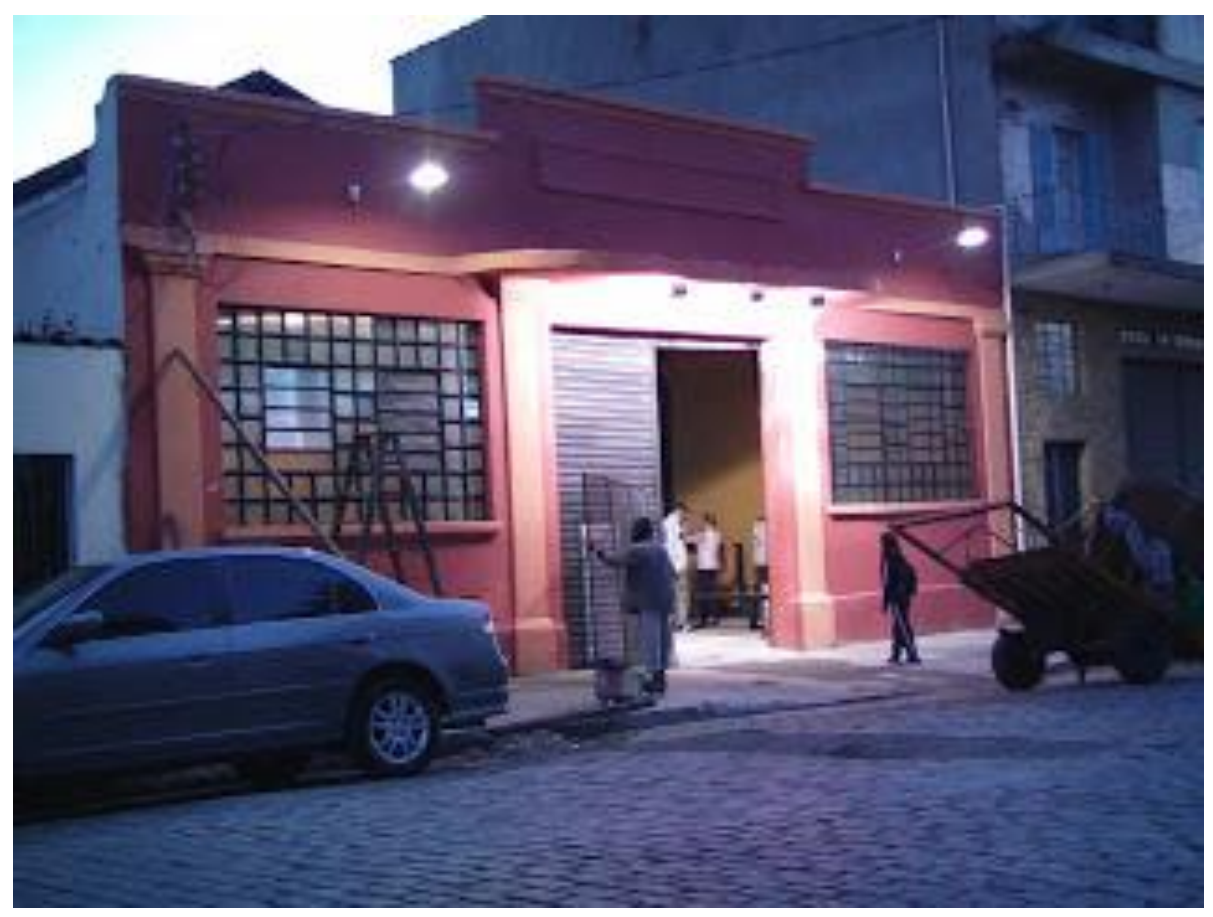

Fonte: Blog Myashiro Teatro 4

A curiosidade dos alunos sobre a peça aumentou quando viram o espaço do teatro e alguns comentaram como é diferente daqueles teatros que já foram ou até mesmo de como imaginavam ser um teatro. A surpresa dos alunos mostra que apesar de gratuitos ou a baixo custo, esse tipo de espaço era, até então, desconhecido por eles. A proximidade entre o teatro e a escola também surpreendeu, já que grande parte dos equipamentos culturais se encontram no centro da cidade.

De acordo com Koudela (2008), para viabilizar o acesso de espectadores ao teatro, deve-se considerar dois aspectos principais: o acesso físico e o acesso simbólico. O acesso físico trata da possibilidade de frequentar aquele espaço, seja por distância, acessibilidade ou viabilidade financeira. Já o acesso simbólico, opera no terreno da linguagem. Trata da relação que o espectador cria com a experiência teatral, desenvolvendo sua autonomia crítica e criativa.

No caso da turma citada, o acesso físico foi plenamente viável, já que o espaço é próximo à instituição educacional e à estação de metrô e, além disso, o ingresso foi disponibilizado gratuitamente. Porém, o grupo, em sua maioria não possui o acesso simbólico, ou seja, o interesse do sujeito em ir ao teatro ou outros espaços

\footnotetext{
${ }^{4}$ Disponível em: <http://miyashiroteatro.blogspot.com/2010/09/oficina-com-o-sobreventogratuito.html>
} 
culturais. Nesse contexto, Koudela (2008) considera a importância da autonomia para a prática cultural.

A autonomia refere-se à construção de sentidos que nasce a partir da experiência sensível, a elaboração de significações que constituem o ato pessoal e intransferível do espectador. Esta autonomia precisa ser construída (p. 5).

A ampliação do acesso simbólico aos equipamentos culturais implica um processo de educação, construção da apreciação e interpretação do espectador. A peça teatral e o espaço cultural suscitam uma outra forma de aprendizagem, relacionando o contexto da obra com a realidade do espectador. Abrem espaço para a construção de novas sensações, de experiências subjetivas que provocam diferentes significados.

Apenas dez alunos puderam participar do debate, já que havia passado das 22 horas. Durante o debate, os membros do grupo teatral falaram sobre o intenso processo de pesquisa e a construção do espetáculo, incentivando a participação da plateia.

Figura 4: Debate com alunos que participaram do espetáculo criado a partir de histórias da vizinhança - Grupo Sobrevento

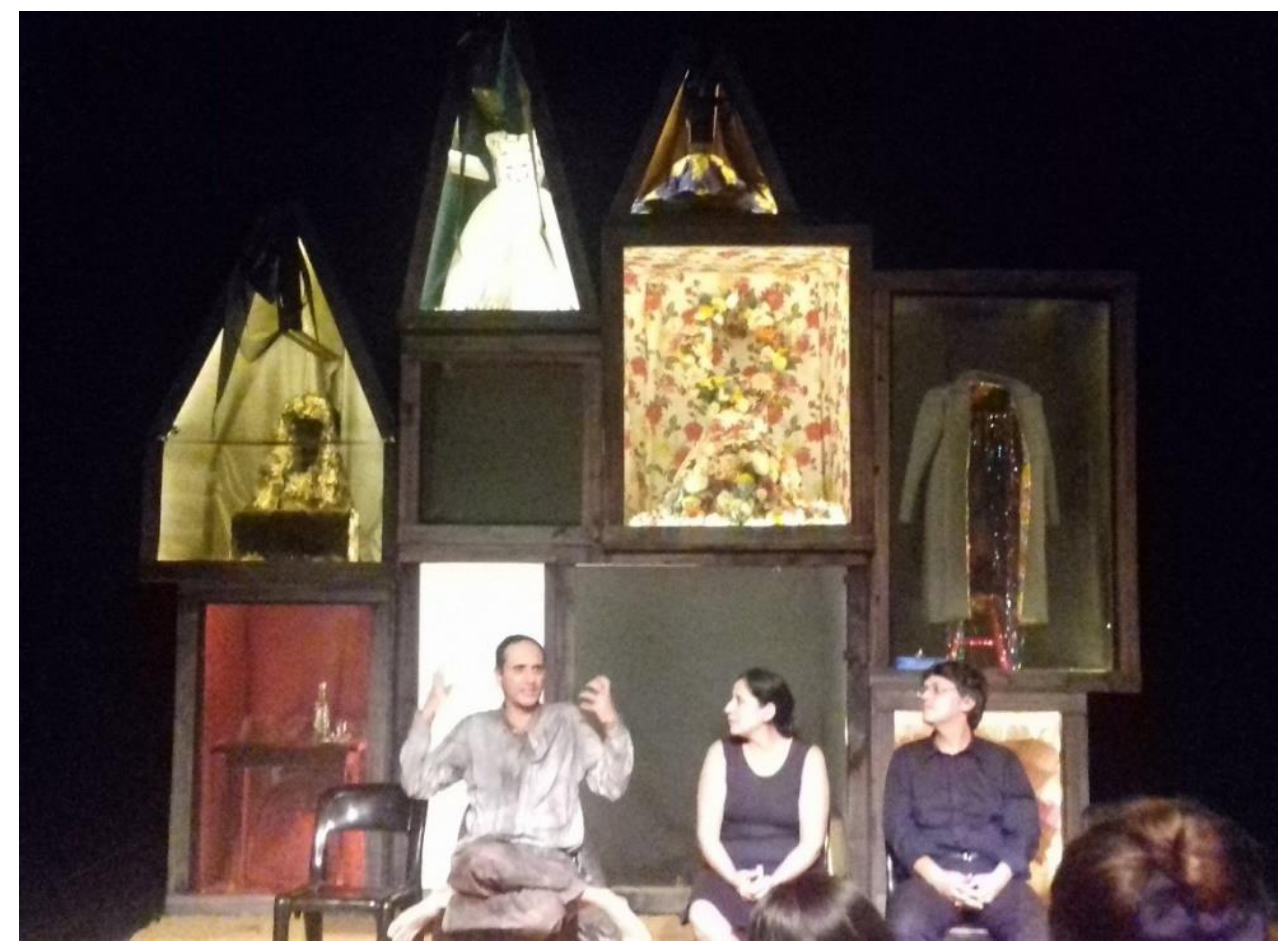

Fonte: Autoria própria

Alguns dos alunos presentes questionaram sobre os símbolos apresentados e os sentimentos despertados pelo espetáculo. Questionaram, por exemplo, o significado da terra que cai ao fim do espetáculo, o anjo que aparece na última cena 
e o formato dos nichos, que alguns diziam parecer uma igreja e outros diziam se assemelhar a caixões. Discutiram também sobre as sensações despertadas: tensão, nervosismo, morbidez e emoção, suscitadas pela trilha sonora, cenário, figurinos, iluminação e outros elementos.

Na semana seguinte, propus uma breve discussão sobre a peça de teatro em sala de aula, questionando quais eram as cenas ou elementos que mais haviam chamado atenção. Alguns disseram se sentir identificados com as memórias dos personagens, outros disseram ter se impressionado com o belo e inusitado cenário/figurino. Houve também aqueles que disseram ter adorado, apesar de "não ter entendido nada". Declarar "não ter entendido nada" pareceu uma forma de se proteger de dizer "coisas erradas" ou contrariar os colegas.

Discutimos, então, sobre a valorização das subjetividades e sentimentos humanos, presentes na arte contemporânea. Mediei a conversa os incentivando a perceber que cada sujeito pode interpretar a obra de uma forma diferente. Que não existem, necessariamente, significados únicos ou respostas certas quando se trata de arte. De acordo com Desgranges (2005):

os significados de uma obra não estão cravados nela como algo inalterável, que está lá e precisa ser entendido pelo espectador, pois se trata menos de entendimento dos significados e mais de construção de significados, que são formulados pelo espectador no diálogo que trava com a obra (p.19).

O autor considera, ainda, que a capacidade para analisar uma peça teatral e outras obras de arte não é somente um talento natural, mas uma conquista cultural. Ou seja, os espectadores podem e devem desenvolver esta capacidade e para isso, é preciso exercitá-la. Tornou-se perceptível que aqueles que possuíam maior dificuldade em compreender e interpretar a peça são também aqueles que não possuem familiaridade com a linguagem artística.

Nesse sentido, Koudela (2008) assinala que "promover o contato com a arte e com o teatro implica vencer preconceitos e bloqueios de ordem afetiva" (p.13). Os alunos são pessoas com diferentes experiências de vida e variados contatos com a cultura. É no diálogo e na interação entre espectador e espetáculo que se constroem os significados da visita ao teatro.

Como atividade avaliativa solicitei refletissem sobre a experiência da visita técnica que os alunos, respondendo às seguintes questões.

1. Você já tinha ido ao teatro anteriormente? Se sim, quantas vezes?

2. O que você achou da estrutura do teatro?

3. Escreva suas impressões sobre o espetáculo (história, atuação, cenário, figurino e sonoplastia).

4. Se você fosse escolher um objeto afetivo para te representar, qual seria? Por quê?

As respostas à primeira questão confirmaram a falta de familiaridade de grande parte da turma com a linguagem teatral. A maior parte disse ter ido poucas vezes ao teatro, apenas na infância, com familiares ou com a escola. 
Já na segunda e terceira pergunta, foi possível considerar que mesmo estando apenas no início do primeiro módulo, os alunos já desenvolviam o olhar crítico do profissional de Eventos ao analisar a infraestrutura, iluminação, sonoplastia, serviço de alimentos e bebidas e hospitalidade do espaço.

Enquanto a última questão, associada a trama da obra, possibilitou a análise de aspectos mais subjetivos dos estudantes despertados pelo espetáculo.

Uma vaquinha de pelúcia que meu irmão pegou pra mim naquelas maquininhas de pegar brinquedo do shopping. Foi a última coisa que meu irmão me deu antes de ir embora de casa. Quando ele me deu ele disse que não importava onde ele estivesse, se era longe ou se era perto, não importava se eu sou lésbica ou se sou hétero, não importa nada, por que eu sempre serei a irmãzinha dele e ele sempre cuidará de mim e me protegerá. (B. P., 20 anos).

Escolheria algo que remetesse a algum presente que dei pra outra pessoa, pois em algum deles coloco muito de mim na tentativa de dar algo único e especial para o outro, e gostaria de ser lembrada dessa forma. (P. S., 25 anos).

O objeto que eu escolheria seria o meu ursinho chamado Bisonho, pois eu o ganhei da minha mãe quando ainda era um bebê. (C. L., 18 anos).

Lembro da tesoura que era de minha mãe e foi uma das poucas coisas que trouxe do Nordeste comigo. Uso até hoje porque sou costureira. (M. L., 50 anos).

A obra de arte pôde ser sentida e interpretada de diferentes formas por cada espectador, de acordo com sua formação histórica, social e cultural. É na conexão com suas próprias memórias que os alunos se relacionaram com o espetáculo e se permitiram vivenciar novos significados. De acordo com Desgranges (2005):

A experiência teatral desafia o espectador a, deparando-se com a linguagem própria a esta arte, decodificar e interpretar os diversos signos presentes em uma encenação. Cada um destes elementos de linguagem colabora para a apresentação da história, e cabe ao espectador articular e interpretar este conjunto complexo de signos, que se renova a cada instante. Este mergulho no jogo da linguagem, que provoca o espectador a elaborar uma compreensão destes variados elementos linguísticos propostos em uma montagem teatral, estimulam-no a exercitar e a apropriar-se desta linguagem. (p. 5).

A vivência dessa linguagem desperta a vontade do espectador de interpretar a própria vida, exercitando a compreensão e reflexão sobre o sujeito, sua história e relação com o mundo. 


\section{CONSIDERAÇÕES FINAIS}

Carvalho (2016) afirma que a "obra de arte se completa na relação com o receptor. Antes deste momento "mágico" ainda há incompletude" (p.15). Ou seja, o espetáculo teatral só cumpre sua função quando entra em contato com o espectador e é por ele compreendido e sentido. Ao perceber a obra, os alunos têm a oportunidade de se colocar em situações diferentes de seu cotidiano, desenvolvendo criatividade e autonomia em relação aos símbolos e significados presentes na sociedade.

A formação estética é de fundamental importância no desenvolvimento humano, pois permite que o espectador consiga perceber as várias expressões artísticas e assim, por consequência, compreender o mundo à sua volta, chegando a transcendê-lo. $O$ desenvolvimento do olhar estético possibilita novos olhares em relação à vida e suas particularidades, pois faz com que o espectador, acostumado a lidar com as várias interpretações oferecidas pelas obras artísticas, construa novos sentidos e reformule suas percepções. (CARVALHO, 2016, p. 12).

A importância da formação estética deve ser considerada também no contexto do técnico do eixo de Lazer, Turismo e Hospitalidade. Um amplo leque cultural e artístico é essencial para esse profissional, e esse tipo de visita técnica possibilita tal expansão. Conhecendo diferentes espaços e formas de expressões culturais, os alunos compreendem a abrangência dos eventos culturais na cidade de São Paulo.

Nas visitas posteriores com a mesma turma (Teatro de Arena e Museu Emma Klabin), os alunos já se sentiram mais confortáveis e confiantes em explorar os espaços, questionar e relacionar símbolos em diferentes contextos históricos e culturais. Alguns deles também começaram a se interessar mais por outras atrações em espaços culturais de São Paulo, me pedindo indicações e até mesmo, comentando sobre os espetáculos que viram. Hoje, já no segundo módulo do curso, vários desses alunos dizem sentir saudade das visitas técnicas feitas na disciplina de Produções de Eventos Culturais e que gostariam de ter mais experiências como essas.

Assim, é necessário o incentivo a visitas técnicas a equipamentos culturais nos cursos técnicos da área. Buscando contextualizar o ambiente e a atividade artística às habilidades exigidas ao profissional de Eventos.

O presente artigo abre portas, também, para futuras pesquisas que pretendam se aprofundar na temática, considerando a importância de experiências culturais para a formação dos profissionais do setor. Compreender o perfil socioeconômico, capital cultural e hábitos de lazer dos alunos dos cursos técnicos de Lazer, Turismo e Hospitalidade podem facilitar a abordagem de professores, preparação de materiais didáticos e desenvolvimento de práticas pedagógicas. Pesquisas com alunos egressos sobre seus hábitos de lazer e cultura posteriores ao curso e absorção do mercado de trabalho de Eventos também podem ser objetos interessantes para reflexões futuras. 


\section{REFERÊNCIAS}

BRASIL. Ministério da Educação. Catálogo Nacional dos Cursos Técnicos.

Brasília: MEC: 2016. Disponível em: <http://portal.mec.gov.br/docman/novembro2017-pdf/77451-cnct-3a-edicao-pdf-1/file> Acesso em: 30 de março de 2019.

CARVALHO, Lidiane de Leles. 0 teatro na formação da percepção estética: um processo de Ensino Aprendizagem. 2016. 45f. Trabalho de Conclusão de Curso (Artes Cênicas), Universidade de Brasília, Brasília, 2016.

CARVALHO, William L. de.; REJOWSKI, Mirian. Tecnologia em eventos da faculdade HOTEC, São Paulo: proposta de formação versus atuação profissional de egressos. Revista de Hospitalidade. V. XI, n 1. Junho, 2012. Disponível em: <https://revhosp.org/hospitalidade/article/view/464/502> Acesso em: 30 de março de 2019.

CEETEPS - CENTRO ESTADUAL DE EDUCAÇÃO TECNOLÓGICA PAULA SOUZA. Plano de curso: Técnico em Eventos. Centro Paula Souza. Governo do Estado de São Paulo. 2013 (atualizado em 2018).

CEETEPS - CENTRO ESTADUAL DE EDUCAÇÃO TECNOLÓGICA PAULA SOUZA. Guia de Profissões Técnicas. Governo do Estado de São Paulo: Centro Paula Souza, 2020. Disponível em: <https://www.cps.sp.gov.br/wpcontent/uploads/sites/1/2019/11/2019_guia_profissoes_tecnicas_final.pdf> Acesso em: 02 de fevereiro de 2020.

DESGRANGES, Flávio. Quando teatro e educação ocupam o mesmo lugar no espaço. In: DESGRANGES, Flávio. Caminho das Artes: A Arte fazendo Escola. São Paulo: Secretaria da Educação do Estado de São Paulo, 2005.

KOUDELA, Ingrid. A ida ao teatro. Sistema Cultura é currículo. Secretaria da Educação do Estado de São Paulo. São Paulo, 2008. Disponível em: <http://culturaecurriculo.fde.sp.gov.br/administracao/Anexos/Documentos/42009063 0140316A\%20ida\%20ao\%20teatro.pdf> Acesso em: 21 out 2019.

MARTIN, Vanessa. Manual prático de eventos: gestão estratégica, patrocínio e sustentabilidade. Rio de Janeiro: Elsevier, 2015.

MEIRA, Marisa Eugênia Melillo. Desenvolvimento e aprendizagem: reflexões sobre suas relações e implicações para a prática docente. Ciência \& educação. Bauru, vol.5, n.2, pp.61-70, 1998. Disponível em: <https://doi.org/10.1590/S151673131998000200006 >. Acesso em: 05 de abril de 2019.

MUSSI, Monica Cristina. Um breve histórico sobre a origem da Pedagogia e suas relações com a vida social. Formação Pedagógica para Educação Profissional. Centro Paula Souza, 2018.

NUNES, Leandro. Em Noite, Grupo Sobrevento ecoa memórias de vizinhos. O Estado de São Paulo. 02 fev 2019. Disponível em:

<https://cultura.estadao.com.br/noticias/teatro-e-danca,em-noite-grupo-sobreventoecoa-memorias-de-vizinhos,70002704241>. Acesso em: 21 out 2019.

OLIVEIRA, Sandra Maria Tabosa de. Práticas de Planejamento e Organização de Eventos. Distrito Federal: Editora IFB, 2016. 
ONISHI, Kelly Miyuki, O profissional do secretariado como organizador de eventos empresariais. Curitiba: Editora PUCPR, 2005.

SOBREVENTO. Espetáculo Noite. Site do Grupo Sobrevento de Teatro.

Disponível em: <http://www.sobrevento.com.br>. Acesso em: 28 de março de 2019.

SPTURIS. São Paulo: cidade do mundo. Dados e fatos dos eventos, viagens e turismo na capital paulista. Observatório do Turismo, 2019. Disponível em: <http://www.observatoriodoturismo.com.br/> Acesso em: 03 de abril de 2019.

ZITTA, Carmen. Organização de eventos: da ideia à realidade. 5. ed. Brasília: SENAC, 2014. 